\title{
Aplicação do Mapeamento Socioambiental na Formação Inicial de Professores: uma Abordagem Metodológica Crítica e Participativa
}

\author{
Denise de La Corte Bacci, Vânia Maria Nunes dos Santos², Lucelene Martins³ \\ 'Departamento de Geologia Sedimentar e Ambiental do Instituto de Geociências da Universidade de São Paulo \\ 'Laboratório de Pesquisas e Práticas em Educação e Sustentabilidade (Lappes/USP) \\ ${ }^{3}$ Departamento de Mineralogia e Geotectônica do Instituto de Geociências da Universidade de São Paulo \\ * Autora para correspondência: bacci@usp.br
}

\section{RESUMO}

O mapeamento socioambiental é um instrumento didático-pedagógico de diagnóstico, planejamento e ação que promove a participação dos diferentes atores sociais na busca pela melhoria da qualidade de vida e na promoção da aprendizagem social. Tendo como objetivo a construção do olhar socioambiental na escola, a metodologia foi utilizada no curso de formação inicial em Geociências e Educação Ambiental, do Instituto de Geociências da USP. Centra-se no desenvolvimento de atividades voltadas ao (re)conhecimento do lugar/ambiente e seus problemas para a formação crítica de professores com capacidade para transformar a realidade socioambiental. $\mathrm{O}$ uso do mapeamento socioambiental resultou em um processo de aprendizagem participativo, dialógico e interdisciplinar, no qual os futuros professores se apropriaram da metodologia.

Palavras-chave: Mapeamento Socioambiental; Formação de Professores; Metodologias Participativas; Aprendizagem Social.

\begin{abstract}
The socio-environmental mapping is a didactic and pedagogical tool of diagnosis, planning and action that promotes the participation of different social actors in searching to improve quality of life and promoting social learning. With the goal of building a socio-environmental vision at school, the methodology was used in the undergraduate training course on Geosciences and Environmental Education, of the Institute of Geosciences at USP. It focus on the development of activities directed to (re)cognition of place/environment and its problems for a critical teacher training able to transform social and environmental reality. Environmental mapping use resulted in participatory, dialogic and interdisciplinary learning process, in which the methodology was appropriated by future teachers.
\end{abstract}

Keywords: Socio-Environmental Mapping; Teacher Education; Participative Methodologies; Social Learning.

\section{O Estudo do Ambiente na Formação de Professores}

As questões socioambientais são abordadas na escola segundo as diferentes orientações de documentos como os PCNs (BRASIL, 1997), a Política Nacional de Educação Ambiental (BRASIL, 1999) e as Diretrizes Curriculares de Educação Ambiental (BRASIL/CNE, 2012). Na formação inicial de professores, no entanto, nem sempre há uma proposta específica voltada para os estudos ambientais e para a Educação Ambiental. Bacci et al. (2015 p. 6) analisaram as disciplinas de educação ambiental oferecidas nos cursos de graduação da USP e obtiveram como resultado uma baixa oferta diante das centenas de disciplinas ministradas. Apenas dezoito disciplinas apresentam educação ambiental no título e, dessas, dez são oferecidas para licenciaturas. Os autores afirmam que:

[...] é necessário promover uma educação política voltada para as questões socioambientais, na qual estudantes passam por processos formativos, construindo conhecimentos, valores e atitudes em busca de uma relação respeitosa e sustentável da 
sociedade humana com o meio ambiente que a integra, se apropriando dessa abordagem em seus fazeres pessoais e profissionais. Além disso, a implantação da Educação Ambiental na Educação Superior é um importante instrumento de trabalho interdisciplinar (BACCI et al., 2015, p. 4).

Para Santos (2011, p. 45), "os diferentes aspectos naturais, culturais, econômicos, políticos e técnicos devem ser considerados no processo de apreensão crítica dos problemas socioambientais estudados, em particular no contexto local e em suas conexões, em contribuição à formação de cidadãos, críticos e participativos frente aos problemas da sua realidade".

O estudo do lugar/ambiente, segundo a autora:

[...] contribui para o estabelecimento de relações dialéticas entre o local e o global no levantamento e na análise de problemas socioambientais, favorecendo a apreensão sistêmica e integrada dos processos que (des)constroem o ambiente e o desenvolvimento de procedimentos didático-pedagógicos. Além disso, subsidia no desenvolvimento de práticas educativas promotoras de atitudes críticas e participativas em colaboração à transformação desse ambiente, em busca da sustentabilidade socioambiental (SANTOS, 2011, p. 67).

Na formação de professores, seja no contexto da formação inicial, seja no âmbito da formação continuada, é importante privilegiar "o conhecimento e a reflexão sobre as relações sociedade-natureza em contribuição ao desenvolvimento de novos valores e práticas docentes" (SANTOS, 2011, p. 45). Vários autores (BACGI, 2009; SANTOS \& COMPIANI, 2009; SANTOS, 2011, 2013; COMPIANI, 2013, 2015) reconhecem, ainda, a importância de se desenvolver na escola a formação de cidadãos capazes de compreender e discutir tais relações, considerando o desenvolvimento do conhecimento científico, em particular os biofísicos, da ciência e da tecnologia (CTSA), para o uso sustentável dos recursos naturais, e também as implicações, dilemas e conflitos socioambientais resultantes do modo de vida atual da sociedade.
Segundo Silva (2009, p. 3), "contribuir com a transformação social e com a construção de práxis pedagógicas inovadoras por meio de metodologias adequadas as suas características é um dos pilares estruturantes da Educação Ambiental Crítica". Nesse sentido, a proposta aqui apresentada toma como pressuposto a EA crítica. A metodologia utilizada é totalmente adequada à promoção de uma nova visão do lugar onde os estudantes vivem, estudam e desenvolvem uma série de atividades educativas, esportivas e culturais, com o objetivo de construir um olhar crítico sobre esse lugar.

Nas proposições de Educação Ambiental brasileira, "o sentido de crítica incorpora a negação do modo de produção hegemônico", ou seja, fundamenta-se numa ideologia de que "não há uma separação entre produção de ideias e condições sociais e históricas em que são produzidas" (SILVA, 2009, p. 4).

O estudo do lugar/ambiente e de seus problemas revela, portanto, a necessidade de se repensar a formação inicial de professores como profissionais críticos e reflexivos, conforme apontam Schön (1992) e Pimenta e Ghedin (2002). Esses autores discutem que profissionais que apresentam uma postura interdisciplinar, construtivista e comunicativa são capazes de compreender tanto as relações sociedade-natureza quanto as implicações da prática pedagógica para o exercício da cidadania, em busca de um ambiente ecologicamente equilibrado e socialmente justo.

Isso implica, sobretudo, "o desenvolvimento de um trabalho pedagógico que considere a crítica e o diálogo e reconheça a importância da ação voltada à construção de uma sociedade melhor para se viver" (SANTOS, 2011, p. 49).

Nesse contexto, os fundamentos da Educação Ambiental Crítica e da Aprendizagem Social contribuem como proposta inovadora para promover a intervenção de diferentes atores locais na elaboração de diagnósticos socioambientais. As práticas educativas que tomam como base os referenciais da Aprendizagem Social apresentam sempre um caráter colaborativo, nas quais são valorizados o diálogo e a participação. Possibilitam ainda a "abertura de um estimulante espaço para a construção 
de eixos interdisciplinares em torno dos quais se tece uma nova cultura para a formação abrangente, a partir de uma abordagem sistêmica e complexa" (JACOBI, 2013, p. 8).

O presente artigo aborda a aplicação de uma metodologia colaborativa, a do mapeamento socioambiental, no contexto de formação inicial de professores no curso de graduação em Licenciatura em Geociências e Educação Ambiental, do Instituto de Geociências da Universidade de São Paulo. O objetivo foi introduzir essas metodologias no contexto de formação inicial, de maneira a promover o exercício de práticas pedagógicas voltadas à formação crítica.

A questão que se pretende analisar no presente texto é qual seria a contribuição do mapeamento socioambiental para a construção de um olhar crítico para o ambiente, na formação inicial de professores.

\section{Pressupostos Teórico-Metodológicos}

Para pensarmos a formação de professores no curso de licenciatura, os pressupostos tomados como referência no campo teórico da Educação Ambiental são o de uma educação ambiental crítica em sua abordagem interdisciplinar, na perspectiva da complexidade e subsidiada pela interpretação histórico-crítica da realidade. Os pressupostos teóricos da Aprendizagem Social (WALS, 2007; JACOBI, 2011, p. 11) também orientaram as práticas colaborativas aplicadas no contexto da formação inicial de professores. O conceito de Aprendizagem Social envolve uma estimulante ideia de desenvolver processos de articulação de ações cuja premissa é a noção de "aprender conjuntamente para manejo e decisões conjuntos e mudanças na gestão" (JACOBI, 2011, p. 21). Basicamente, a estratégia de aprendizado é que todos devem conhecer o contexto de criticidade e condições de governança para intervirem juntos em contextos caracterizados pela degradação ambiental. A Aprendizagem Social serve de base para buscar responder aos desafios da sustentabilidade e à integração das interfaces da gestão de recursos naturais, o que, segundo Jacobi (2013, p. 7), "pressupõe a contribuição de diferentes conhecimentos e interdisciplinaridade".
Esses pressupostos afirmam o caráter participativo, permanente e político da dimensão ambiental no processo educativo (BRASIL, 1999; MMA, 2005; LOUREIRO, 2004; FESTOSO \& TOZONI-REIS, 2012). As metodologias participativas aplicadas ao contexto educativo visam a contribuir com a transformação social e com a construção de práxis pedagógicas inovadoras. A formação de professores que possam refletir sobre as questões ambientais de abordagens dialógica, inclusiva, participativa, crítica, transformadora e emancipatória, voltadas a uma cidadania ativa, é o que se deseja no curso de licenciatura em questão.

Os referenciais metodológicos aqui apresentados discutem as possibilidades de intervenção e proposição de práticas educativas (SANTOS, 2011, 2013; PONTUSCKHA, 2006; ANDRADE \& FURLAN, 2011; CRACEL, 2015; COMPIANI, 2015) que consideram, desde a formação inicial, aspectos importantes para o professor atuar na escola e na comunidade de forma a promover transformações da realidade socioambiental.

\section{O Mapeamento Socioambiental como Prá- tica Pedagógica na Formação do Professor}

O mapeamento socioambiental é um recurso didático-pedagógico para o (re)conhecimento do lugar/ambiente. Contribui no levantamento de informações socioambientais para a elaboração de diagnóstico da realidade local e subsidia a reflexão sobre as formas de uso e ocupação do espaço mapeado e suas implicações para a qualidade de vida dos seus moradores (SANTOS, 2011, pp. 39-40). Essa metodologia foi desenvolvida junto à disciplina voltada aos aspectos metodológicos da educação ambiental, como aponta o Artigo 10 da Política Nacional de Educação Ambiental, instituída pela Lei n. 9795/99, no desenvolvimento dos estágios supervisionados.

O mapa se constitui num produto de construção coletiva e colaborativa dos participantes, representando a realidade local. Ele contribui para transformar informação em conhecimento e estabelecer uma ponte entre o científico e o cotidiano (significado). Considera os seguintes procedimentos, segun- 
do Bacci e Santos (2013, p. 20): a) a realidade em que vive o indivíduo, o modo como lida com o seu meio ambiente imediato e a compreensão que tem dele, como ponto de partida; b) a possibilidade de reelaboração da compreensão inicial do indivíduo sobre o seu meio ambiente como ponto de chegada do processo de ensino e aprendizagem; c) o caminho para o desenvolvimento de diferentes tipos de saber, tendo em vista a construção do conhecimento mais elaborado e mais crítico.

No presente artigo, a metodologia do mapeamento foi utilizada para o reconhecimento do lugar em que os alunos estudam, vivem e passam grande parte do seu tempo, ou seja, o próprio campus da universidade. A metodologia foi usada no contexto da disciplina 0440418 - Práticas de Educação Ambiental com ênfase em Geociências, ministrada no sexto período do curso de graduação em licenciatura em Geociências e Educação Ambiental do Instituto de Geociências, da Universidade de São Paulo. Os dados aqui apresentados foram coletados em quatro anos de utilização dessa metodologia na disciplina (entre 2011 e 2014). O objetivo foi promover a reflexão e o debate sobre as possibilidades das metodologias e práticas participativas e de pesquisa em Geociências e Educação Ambiental para o desenvolvimento dos projetos de estágio supervisionado. Nesse contexto, foram analisados os mapas mentais e mapas síntese-propositivos produzidos em grupo, por oitenta alunos que cursaram a disciplina nesse período.

\section{Construção do Mapa e Etapas de Desenvolvimento}

A elaboração do mapa socioambiental foi realizada em uma parte do campus da USP Butantã, tendo como objetivos:

-Elaborarumdiagnósticoparticipativodarealidade socioambiental local, visando ao (re)conhecimento do lugar, seus problemas e conflitos;

- Promover diálogos e subsidiar reflexões coletivas sobre a realidade socioambiental local;

- Elaborar mapas-síntese propositivos como produto das reflexões sobre o local.
A fim de que os mapas socioambientais possam atender a tais objetivos, devem desenvolver-se de forma a propiciar condições para:

- $(\mathrm{Re})$ conhecer o local em que se vive, trabalha ou estuda;

- Refletir sobre esse local, seus problemas e conflitos;

- Dialogar sobre a realidade socioambiental em busca de soluções pactuadas para os problemas/ conflitos identificados, visando à transformação do ambiente e à melhoria da qualidade de vida.

As etapas de desenvolvimento seguiram a proposta de Santos e Bacci (2011, p. 62) e Bacci e Santos (2013, pp. 20-21), sendo:

- $1^{a}$ etapa: Elaboração do mapa mental. Realizada antes da ida a campo, objetivando resgatar a percepção dos alunos sobre o campus; nesse momento, os alunos identificam os locais físicos que conhecem no campus e as sensações que têm desses locais, tais como medo, frio e calor, alegria, tristeza, liberdade, contemplação, entre outras.

- $2^{\text {a }}$ etapa: Elaboração do mapa socioambiental. Visa ao levantamento de diferentes aspectos socioambientais em campo para o diagnóstico da realidade local, tais como: cursos d'água, áreas verdes, construções, estado das ruas e calçadas, disposição de resíduos, serviços diversos presentes; espaços de lazer e cultura; segurança, infraestrutura, entre outros. Nesse momento, os alunos confirmam ou não os conhecimentos e as impressões em relação ao local.

- $3^{\text {a }}$ etapa: Preparação do mapa síntese. Momento em que o grupo de alunos dialoga sobre os mapas socioambientais elaborados, ou melhor, sobre as diferentes percepções e problemas observados individualmente em campo, visando à construção de um mapa coletivo pactuado, síntese dos principais problemas/conflitos locais para o grupo. O mapa-síntese é interativo e dinâmico, construído e reconstruído a partir de "problematizações" sobre questões/conflitos da realidade socioambiental local.

- $4^{\mathrm{a}}$ etapa: Construção do mapa propositivo.

Este mapa é resultado do processo coletivo de reflexão e diálogo sobre os problemas e conflitos locais, os quais foram levantados em campo e representados no mapa-síntese. Neste mapa são apresentadas 
propostas para definir as ações e as responsabilidades individuais e coletivas para a melhoria da qualidade de vida no local.

Os alunos foram orientados a representar sua percepção sobre o lugar durante o trabalho de campo por meio de um roteiro com perguntas e um mapa impresso do campus. O trabalho foi desenvolvido no período noturno no campus, no horário das aulas, e o percurso foi definido em conjunto entre professores e alunos. Isso torna o diagnóstico local interessante, uma vez que muitos alunos não têm o hábito de circular no campus nesse horário, promovendo, provavelmente, uma dinâmica diferente da que seria observada no período diurno. Os alunos se dividiram em grupos e fizeram o mesmo percurso.

Os mapas apresentados no presente artigo (Figuras 1 a 3) ilustram as percepções dos alunos sobre o campus da USP Butantã, em São Paulo. Tais percepções apontam tanto elementos concretos por eles identificados (prédios, ruas, bancos, lagos etc.), como sensações (alegria, medo, ansiedade, fome etc.). O mapa da Figura 3 apresenta a síntese dos dados dos grupos obtidos no levantamento de campo e posteriormente analisados em sala de aula.

Observa-se que as representações dos alunos estão diretamente relacionadas com o tempo de permanência e os lugares que frequentam. Os alunos que moram no Conjunto Residencial (Crusp), por exemplo, apresentam percepções mais aguçadas e detalhadas do campus, diferentemente daqueles que frequentam os institutos apenas no horário das aulas. Durante o trabalho de campo todos os alunos, incluindo os moradores do campus, descobriram locais que não conheciam e muitos deles mudaram sua percepção após o diagnóstico e a discussão sobre o lugar. Os olhares para o campus apresentaram-se muito variados, mas, de forma geral, foram críticos em relação ao lugar estudado. A elaboração do mapa proporcionou uma análise crítica da realidade e levou à discussão sobre diferentes temas ambientais: produção de diferentes resíduos sólidos e formas de coleta seletiva, abastecimento de água, identificação de áreas verdes e áreas com excesso de construções, segurança, iluminação,

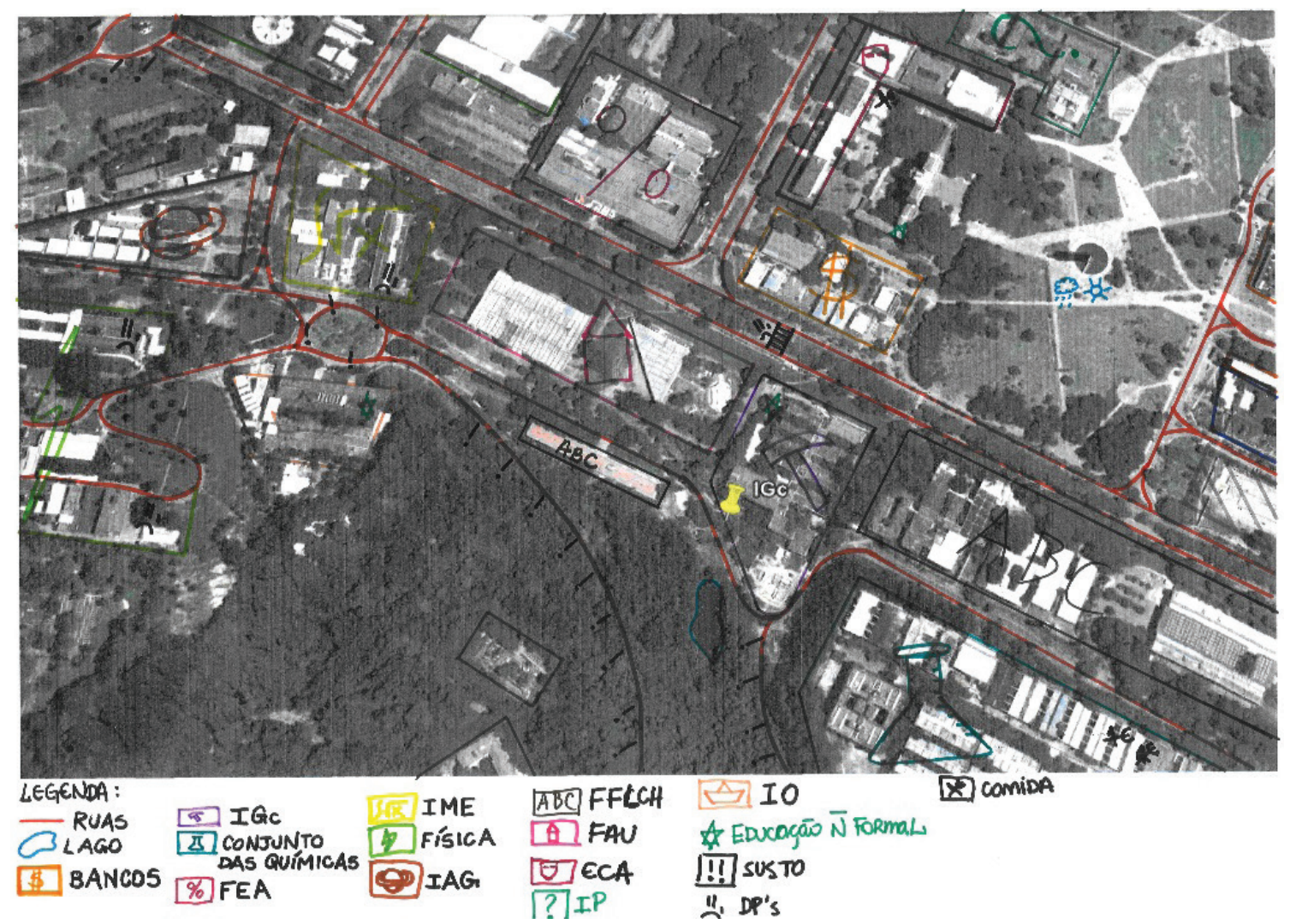

Figura 1- Mapa mental produzido por um dos grupos de alunos da disciplina de Práticas de Educação Ambiental com ênfase em Geociências em 2014, mostrando elementos concretos do campus da USP-Butantã. A base do mapa foi obtida a partir da imagem de satélite do Google Earth (2011). A legenda do mapa criada pelos alunos destaca o espaço físico. 


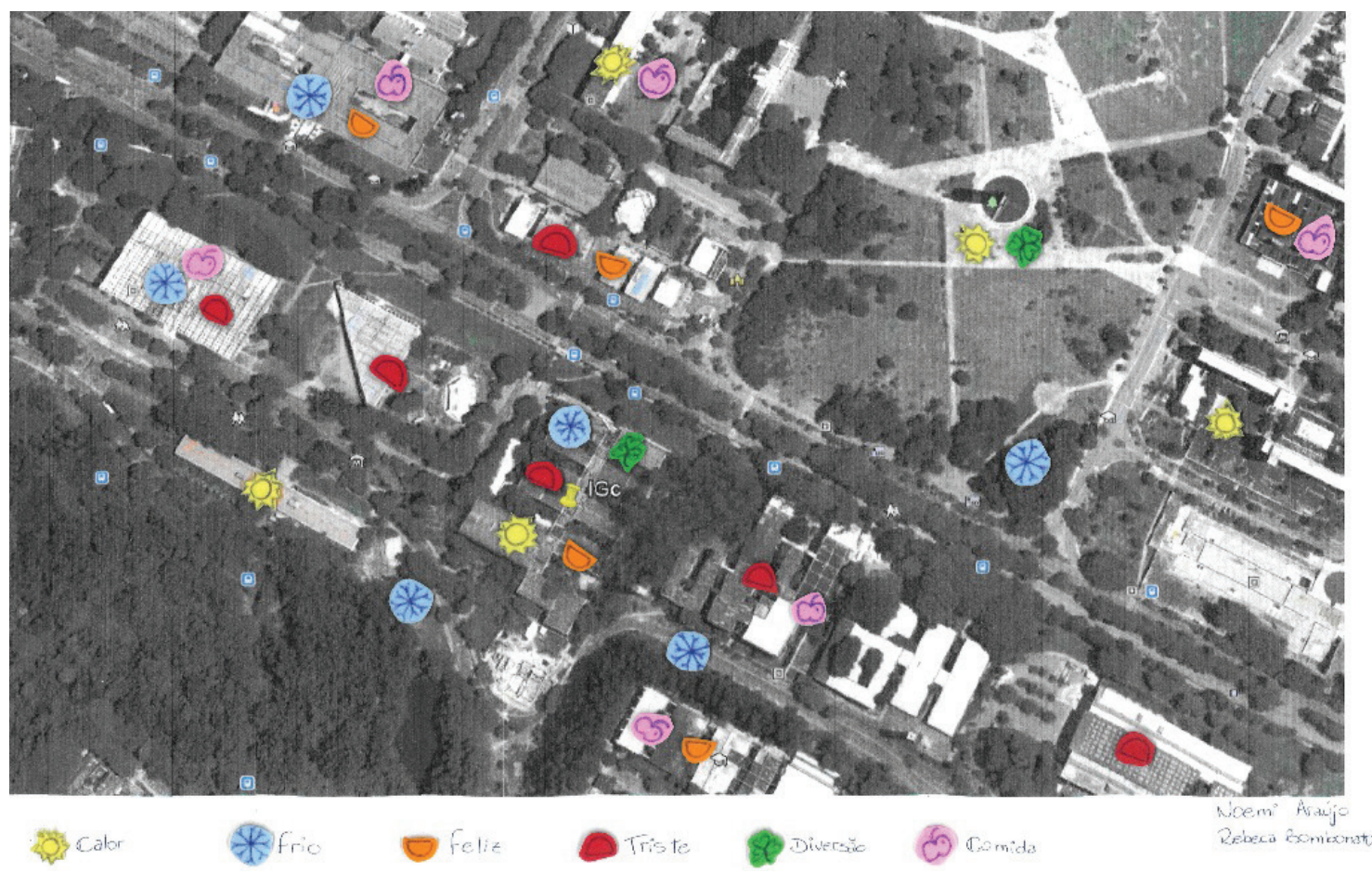

Figura 2 - Mapa mental produzido por um dos grupos de alunos da disciplina de Práticas de Educação Ambiental com ênfase em Geociências em 2014, mostrando as sensações dos alunos ao percorrerem o campus da USP-Butantã. A base do mapa foi obtida a partir da imagem de satélite do Google Earth (2011). A legenda do mapa criada pelos alunos destaca a percepção do lugar.

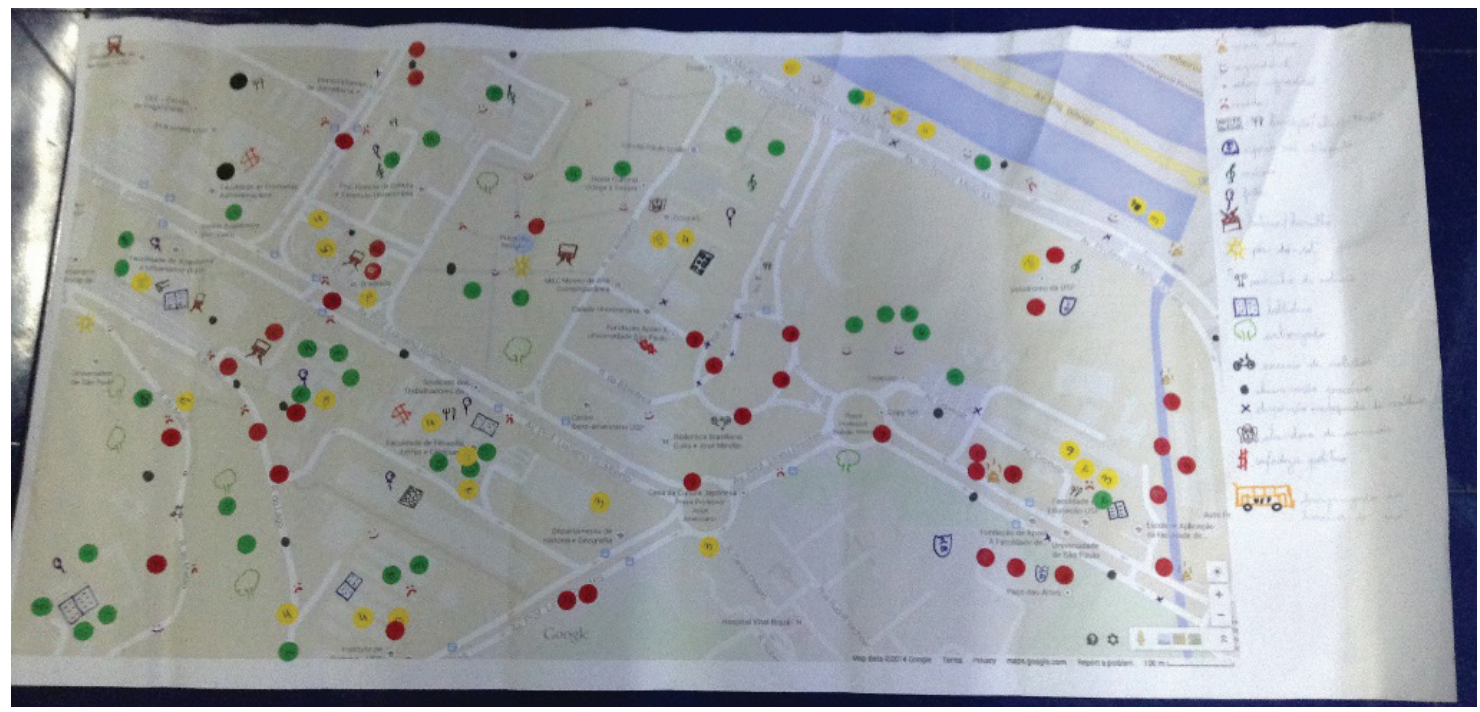

Figura 3 - Mapa síntese-propositivo do campus da USP-Butantã produzido por grupo de alunos da disciplina de Práticas de Educação Ambiental com ênfase em Geociências em 2014. A base do mapa foi obtida a partir do Google Maps (2011) e a área mapeada corresponde a aproximadamente $3 \mathrm{~km}^{2}$. A legenda do mapa criada coletivamente pelos alunos representa os diversos olhares sobre o lugar. Os pontos coloridos em destaque no mapa indicam a criticidade dos diferentes lugares observados e a diferença de percepção dos grupos (vermelho = muito crítico; amarelo = pouco crítico; verde = não crítico).

acessibilidade, velocidade de deslocamento de veículos e presença de ciclistas, utilização de alguns espaços, espaços de lazer e cultura, entre outros. Foram também relatadas sensações relacionadas a alegria, preocupação, medo, liberdade, ansiedade, incômodo com barulhos, percepção de cheiros bons e ruins. Todas essas sensações foram discutidas durante a confecção 
do mapa-síntese, refletindo-se sobre o porquê de os lugares as despertarem.

Bacci e Santos (2013, p. 26) identificaram três categorias de análise dos elementos ambientais expressos nos mapas, duas das quais podemos reconhecer nos mapas estudados: a primeira refere-se ao momento de reflexão, no qual os alunos refletem sobre o que foi observado no campus e constroem relações com o real, como resultado da problematização da percepção visual direta; e a segunda como o momento de transformação, no qual os alunos percebem o lugar de forma crítica e apresentam sugestões de mudança. Os indicadores dessas duas categorias estão presentes na identificação dos índices de criticidade (representados por etiquetas das cores do semáforo e que indicam uma classificação em relação à qualidade ambiental - Figura 3) e na elaboração de propostas para a transformação do lugar, visando à sustentabilidade socioambiental.

\section{Considerações Finais}

As experiências com os alunos da graduação mostraram que a metodologia do mapeamento socioambiental propicia maior envolvimento, estímulo à participação e respeito às diferenças de opiniões, criando espaços de diálogo e reflexão sobre o lugar. A metodologia utilizada configura-se como um importante instrumento formativo para o professor, contribuindo para a possibilidade de inserção de novas metodologias de ensino e aprendizagem na sua prática pedagógica, voltadas à educação para a sustentabilidade.

Uma vez apreendida na formação inicial dos professores, a elaboração do diagnóstico do lugar com base no mapeamento socioambiental poderá promover o desenvolvimento de projetos socioambientais escolares voltados ao estudo do lugar/ ambiente onde a escola se localiza. Isso ocorre a partir de uma reflexão crítica e da contextualização de conteúdos curriculares, como já observou Santos (2011, p. 110) na formação continuada de professores. Inserida na escola, essa metodologia poderá contribuir na formação de "leitores críticos do espaço", propiciando aos alunos condições para: saber ler/interpretar o espaço em estudo, saber pensar o espaço em suas relações e saber transformar/fazer o espaço. Assim, colabora para a formação de cidadãos críticos e participativos, sujeitos do seu próprio ambiente, segundo os PCNs (BRASIL, 1997) e as Diretrizes Curriculares de Educação Ambiental (BRASIL/CNE/CP n. 2, 2012).

A avaliação de metodologias participativas torna-se importante, de modo a adequá-las à criticidade proposta pela Educação Ambiental e pela Aprendizagem Social. Pode-se afirmar que os pressupostos dessas duas áreas configuram-se de grande relevância na formação inicial de professores no estudo do ambiente e na ambientalização curricular.

\section{Referências Bibliográficas}

ANDRADE, Julia Pinheiro \& ANGELO FURLAN, Sueli. "Programa Mapa de Educação, Geografia e Meio Ambiente". Revista Geográfica de América Central, vol. II, 2011, pp. 1-14.

BACGI, Denise de La Corte. "A Contribuição do Conhecimento Geológico para a Educação Ambiental". Pesquisa em Debate, edição 11, vol. 6, n. 2, jul./dez. 2009.

\& SANTOS, Vânia Maria Nunes. "Mapeamento Socioambiental como Contribuição Metodológica à Formação de Professores e Aprendizagem Social". Geol. USP, Publ. Espec., São Paulo, vol. 6, ago. 2013, pp. 1-28.

; SILVA, Rosana Louro Ferreira \& SORRENTINO, Marcos. "Educação Ambiental e Universidade: Diagnóstico Disciplinar para Construção de uma Política Ambiental". VIII Epea - Encontro Pesquisa em Educação Ambiental. Rio de Janeiro, jul. 2015.

BRASIL. Ministério da Educação (MEC). Parâmetros Curriculares Nacionais. Brasília. MEC/SEF, 1997.

BRASIL. Ministério do Meio Ambiente (MMA) Departamento de Educação Ambiental (DEA). Encontros e Caminhos da Educação Ambiental: Formação de Educadoras(es) Ambientais e Coletivos Educadores, vol. 1. Brasília, Ministério do Meio Ambiente, 2005. 358 p.

BRASIL. Lei n. 9795, de 27 de Abril de 1999. Dispõe sobre a Educação Ambiental, Institui a Política Nacional de Educação Ambiental e Dá Outras Providências. Diário Oficial da União, 28 abr. 1999.

BRASIL/CONSELHO NACIONAL DE EDUCAÇÃOO. Resolução CNE/CP n. 2. Estabelece as Diretrizes Curriculares Nacionais para a Educação Ambiental, 15 jun. 2012.

COMPIANI, Maurício (org.). Ribeirão Anhumas 
na Escola: Projeto de Formação Continuada Elaborando Conhecimentos Relacionados à Ciência, à Sociedade e ao Ambiente. Curitiba, PR: Editora GRV, 2013. 250 p.

COMPIANI, Maurício. "Aprofundando a Concepção de Pedagogia Crítica do Lugar/Ambiente". In: COMPIANI, Maurício (org.). Ribeirão Anhumas na Escola: Pesquisa Colaborativa entre Escola e Universidade Gerando Conhecimentos Contextualizados e Interdisciplinares. Curitiba, PR: Editora GRV, 2015, pp. 179-202.

CRACEL, Viviane Lousada. "A Importância do Mapa na Construção do Conhecimento". In: COMPIANI, Maurício (org.). Ribeirão Anhumas na Escola: Pesquisa Colaborativa entre Escola e Universidade Gerando Conhecimentos Contextualizados e Interdisciplinares. Curitiba, PR: Editora GRV, 2015, pp. 127-146.

FESTOZO, Marina Battistetti \& TOZONI-REIS, Marília Freitas de Campos. "Ambientalização Curricular no Ensino Superior: Problematizando a Formação de Educadores Ambientais". XVI Endipe - Encontro $\mathrm{Na}$ cional de Didática e Práticas de Ensino. Unicamp, Campinas, 2012, pp. 13-23.

JACOBI, Pedro Roberto. "Aprendizagem Social e Formação de Professores em Educação para a Sustentabilidade Socioambiental". Geol. USP, Publ. Espec., São Paulo, vol. 6, ago. 2013, pp. 5-10.

(org.). Aprendizagem Social - Diálogos e Ferramentas Participativas: Aprender funtos para Cuidar da Água. São Paulo: IEE-USP, 2011. 83 p.

LOUREIRO, Carlos Frederico Bernardo. "Educar, Participar e Transformar em Educação Ambiental". REVBEA, Revista Brasileira de Educação Ambiental. Brasília, n. 0, pp. 13-20, 2004.
PIMENTA, Selma Garrido \& GHEDIN, Evandro. (orgs.). Professor Reflexivo no Brasil: Gênese e Crítica de um Conceito. São Paulo: Cortez, 2002.

PONTUSCKHA, Nídia Nacib. "O Estudo do Meio, Interdisciplinaridade e Ação Pedagógica". Encontro Nacional de Geógrafos, 14, 2006, Rio Branco, AC. Anais... Rio Branco, AC.

SANTOS, Vânia Maria Nunes. Educar no Ambiente: Construção do Olhar Geocientífico e Cidadania. São Paulo: Annablume, 2011, Coleção Cidadania e Meio Ambiente.

"Ensino em Geociências no Estudo do Ambiente: Contribuições à Formação de Professores e Cidadania". Geol. USP, Publ. Espec., São Paulo, vol. 6, ago. 2013, pp. 1-18.

. \& BACCI, Denise de La Corte. "Mapeamento Socioambiental para Aprendizagem Social". In: JACOBI, Pedro Roberto (org.). Aprendizagem Social Diálogos e Ferramentas Participativas: Aprender funtos para Cuidar da Água. São Paulo: IEE-USP, 2011, pp. 61-83.

. \& COMPIANI, Maurício. "Formação de Professores para o Estudo do Ambiente: Projetos Escolares e a Realidade Socioambiental Local". Revista Terre Didática, Campinas, vol. 5, n. 1, 2009, pp. 72-86.

SCHÖN, David. "Formar Professores como Profissionais Reflexivos". In: NÓVOA, A. (org.). Os Professores e sua Formação. Lisboa: Dom Quixote, 1992, pp. 77-92.

SILVA, Luciana Ferreira. "Educação Ambiental Crítica e Gestão Escolar". Pesquisa em Debate, edição 10, vol. 6, n. 1, jan./jun. 2009.

WALS, Arjen (org.). Social Learning towards a Sustainable World: Principles, Perspectives and Praxis. Wageningen: Wageningen Academic Publishers, 2007. 